\title{
Testosterone replacement therapy among elderly males: the Testim Registry in the US (TRiUS)
}

This article was published in the following Dove Press journal:

Clinical Interventions in Aging

22 August 2012

Number of times this article has been viewed

\author{
Rajib K Bhattacharya' \\ Mohit Khera ${ }^{2}$ \\ Gary Blick ${ }^{3}$ \\ Harvey Kushner ${ }^{4}$ \\ Martin M Miner ${ }^{5}$ \\ 'Department of Internal Medicine, \\ University of Kansas Medical \\ Center, Kansas City, KS, USA; ${ }^{2}$ Scott \\ Department of Urology, Baylor \\ College of Medicine, Houston, TX, \\ USA; ${ }^{3}$ Circle Medical LLC, Norwalk, \\ CT, USA $;{ }^{4}$ Biometrics, Auxilium \\ Pharmaceuticals, Malvern, PA, USA; \\ ${ }^{5}$ Men's Health Center, Miriam \\ Hospital, Providence, RI, USA
}

Correspondence: Rajib K Bhattacharya Department of Internal Medicine, Division of Endocrinology, Metabolism and Genetics, University of Kansas Medical Center, 390I Rainbow Blvd, MS2024, Kansas City, KS 66I60, USA $\mathrm{Tel}+19132594114$

Fax + I 9135884060 Email bhattara@yahoo.com; rbhattacharya@kumc.edu
Background: Testosterone levels naturally decline with age in men, often resulting in testosterone deficiency (hypogonadism). However, few studies have examined hypogonadal characteristics and treatment in older ( $\geq 65$ years) men.

Objective: To compare data at baseline and after 12 months of testosterone replacement therapy (TRT) in hypogonadal men $\geq 65$ vs $<65$ years old. Data for participants $65-74$ vs $\geq 75$ years old were also compared.

Methods: Data were from TRiUS (Testim Registry in the United States), which enrolled 849 hypogonadal men treated with Testim ${ }^{\circledR} 1 \%$ (50-100 mg testosterone gel/day) for the first time. Anthropometric, laboratory, and clinical measures were taken at baseline and 12 months, including primary outcomes of total testosterone (TT), free testosterone (FT), and prostate-specific antigen (PSA) levels. Comparisons of parameters were made using Fisher's exact test or analysis of variance. Nonparametric Spearman's $\rho$ and first-order partial correlation coefficients adjusted for the effect of age were used to examine bivariate correlations among parameters.

Results: Of the registry participants at baseline with available age information, 16\% (133/845) were $\geq 65$ years old. They were similar to men $<65$ years old in the duration of hypogonadism prior to enrollment ( $\sim 1$ year), TT and FT levels at baseline, TT and FT levels at 12-month follow-up, and in reported compliance with treatment. Older patients were more likely to receive lower doses of TRT. PSA levels did not statistically differ between groups after 12 months of TRT $(2.18 \pm 2.18 \mathrm{ng} / \mathrm{mL}$ for $\geq 65 \mathrm{vs} 1.14 \pm 0.84 \mathrm{ng} / \mathrm{mL}$ for $<65$ years old, $P=0.1)$. Baseline values for the $>75$-year-old subcohort were not significantly different from subcohorts aged $65-74$ years and $<65$ years.

Conclusion: Hypogonadal men $\geq 65$ years old showed significant benefit from TRT over 12 months, similar to that found for hypogonadal men $<65$ years old. TRT was well tolerated in older patients, successfully increased testosterone level regardless of age, and did not significantly increase PSA levels in older men.

Keywords: male hypogonadism, elderly, testosterone replacement therapy, testosterone gel, TRiUS registry, Testim

Testosterone deficiency (TD), also called hypogonadism, is a relatively common condition, with an estimated prevalence of 2.4 million among US men 40-69 years old. ${ }^{1}$ Decline in testosterone, shown to occur with aging, may negatively affect health and quality of life. ${ }^{2-5}$ TD has been associated with frailty as well as age-related declines in bone mineral density, muscle mass and strength, physical function, and sexual function, and with metabolic changes involving abdominal obesity, metabolic syndrome progressing to type 2 diabetes, insulin resistance, impaired glucose tolerance, negative changes in low-density lipoprotein (LDL) cholesterol, low-density lipoprotein/high- 
density lipoprotein (HDL) cholesterol ratios, and depression. ${ }^{5-13}$ Studies focused specifically on men $\geq 64$ years old have shown associations between low testosterone and lower muscle mass, strength, and physical performance. ${ }^{14-17}$

The treatment of TD in older men has generated some debate. Current Endocrine Society clinical practice guidelines recommend offering testosterone replacement therapy (TRT) on an individualized basis to men with repeatedly measured low testosterone levels and clinically significant signs of hypogonadism; however, a consensus has not been reached on the serum testosterone levels below which TRT is recommended (ie, below 280-300 ng/dL [9.7-10.4 nmol/L], the lower limit of normal for healthy young men, or below a more stringent $200 \mathrm{ng} / \mathrm{dL}[6.9 \mathrm{nmol} / \mathrm{L}]) .{ }^{6}$ This is further complicated in older men with TD (eg, late onset hypogonadism) since it is unclear what "normal" testosterone levels may be for this population and when TRT should be used, especially in a frail elderly population. ${ }^{18}$ Furthermore, safety concerns regarding prostate cancer and cardiovascular events remain important topics in treating older men with TD. It may be for these reasons that TD is often underdiagnosed and undertreated in middle-aged and older men. ${ }^{9,19}$ Additionally, symptoms of TD may be dismissed as signs of aging because they develop slowly and overlap with other common disorders in older men, and patients can have low-normal or borderline testosterone levels, but still show symptoms due to variations in androgen sensitivity. ${ }^{18}$

The ongoing questions regarding TRT in older men with TD may be due to a lack of naturalistic data on whether and how men $\geq 65$ years old are treated for TD in clinical practice settings compared with middle-aged men. To address these questions, we report on data from men enrolled in the Testim Registry in the United States (TRiUS), the first prospective, observational cohort registry of hypogonadal men on TRT. TRiUS enrolled a large sample of TD patients from a variety of clinical settings in the United States with the objective of quantifying symptoms and comorbidities of these patients and their response to Testim ${ }^{\circledR}$ 1\% gel (Auxilium Pharmaceuticals, Malvern, PA), a topical testosterone gel formulation for TRT. This analysis compares TRiUS baseline and 12-month follow-up data for hypogonadal men $\geq 65$ vs $<65$ years old. Data for participants $65-74$ vs $\geq 75$ years old are also compared.

\section{Patients and methods}

\section{Study design}

TRiUS was a prospective, 12-month, observational cohort registry of hypogonadal men who were prescribed Testim by their physicians for the first time. The study was designed to collect data from a large diverse group of men with TD in "real-world" clinical practice settings. As an observational registry study, specific detailed methods used to measure parameters were not prespecified. All parameters were measured or defined according to the investigator's customary practice, including threshold testosterone levels used for diagnosis, time of blood draw for testosterone determination, number of times testosterone levels were measured for diagnosis, placement of measuring tape for waist and hip circumference, and method of blood pressure (BP) determination. TD was also determined according to the customary procedure of the prescribing physician. All laboratory measures were performed and reported independently, and were not overseen by a central laboratory. Prescription dosing was determined by the prescribing physician and could be modified as needed during the 12-month observational period. Follow-up visits were in person with the prescribing physician. Compliance with prescription was recorded daily by patients using diary cards at home. The TRiUS study was not designed to assess safety nor was it a mobility and frailty study. Adverse events were reported according to the usual procedures for postmarket products.

Data were collected at baseline (screening and Day 0) and during suggested follow-up visits at months 1, 3, 6, and 12, although as a registry study these follow-up visits were not mandatory for inclusion. Patients could discontinue participation at any time for any reason. Registry and data collection were managed by Outcome Sciences, Inc (Cambridge, MA). Site monitoring was also performed by Outcome Sciences. Individual sites were responsible for entering patient data and forms into a secure Internet-based electronic data capture (EDC) registry database. All sites were fully trained in the use of the EDC system and had local or central Institutional Review Board (IRB) approval.

\section{Enrollment and assessments}

Potential sites for registry enrollment were identified based on a database of testosterone prescribers. With the goal of enrolling 1000 patients, 931 sites were approached for participation. Methods of approach included postcard advertisement, phone calls, faxes, and field personnel contact. Participating investigators selected patients based on prespecified inclusion/exclusion criteria. The complete methods and baseline characteristics of the entire registry population have been published previously. ${ }^{20}$

\section{Inclusion criteria}

Eligibility was restricted to hypogonadal men who were prescribed Testim by their physicians for the first time. 
Patients who were testosterone naïve or who had received testosterone formulations other than Testim were eligible to participate. To be enrolled, patients must have voluntarily signed and dated an informed consent form reviewed by each site's IRB. The registry was designed so that no data could be entered unless a signed informed consent form was on file. Subgroups studied included patients with erectile dysfunction (ED), ${ }^{21}$ patients reporting depressive symptoms, ${ }^{22}$ patients taking opioids, ${ }^{23}$ patients with HIV/AIDS, ${ }^{24,25}$ patients with metabolic syndrome, ${ }^{26}$ and patients with very low total testosterone levels $(<200 \mathrm{ng} / \mathrm{dL}[6.9 \mathrm{nmol} / \mathrm{L}])$ at baseline ${ }^{20}$ as well as an analysis of prostate health among TRiUS participants. ${ }^{27}$

\section{Exclusion criteria}

Patients were excluded from the study if they had a known sensitivity to any ingredient in Testim, including testosterone, or had carcinoma of the breast or known/suspected carcinoma of the prostate.

\section{Laboratory and clinical measurements}

Laboratory measurements were defined and taken according to the prescribing physician's customary practice, including threshold testosterone levels used for TD diagnosis, time of blood draw for testosterone determination, and number of times testosterone levels were measured for diagnosis.

At baseline and follow-up appointments, the following were assessed: total testosterone (TT), free testosterone (FT), prostate-specific antigen (PSA) levels, plasma glucose level, anthropometrics (ie, weight, waist circumference, hip circumference), cardiovascular measures (ie, systolic BP, diastolic BP, total cholesterol, HDL cholesterol, LDL cholesterol, triglycerides), body mass index (BMI), comorbid health conditions, and current medication use for ED, depression, and pain.

Suggested follow-up visits were at approximately 1, 3, 6, and 12 months after the initiation of therapy, although actual follow-up visits were at the discretion of the physician. Data from visits occurring at Day 330 post initiation, or closest to Day 360, were grouped into the 12-month time point and used for the analysis. Before application of the first dose of TRT, a physical examination, measurement of BMI, recording of concomitant medications, and issuance of patient diary cards for recording daily testosterone gel usage were completed. The primary 12-month outcomes were TT, FT, and PSA levels.

\section{Statistical analysis}

Demographics were summarized for patients $\geq 65$ vs $<65$ years old. Secondary analyses were performed to characterize the patients $\geq 75$ years old vs patients $65-74$ and $<65$ years old. No imputations for missing data were performed. Sample sizes are provided for all analyses. Mean \pm standard deviation (SD) is presented for all numerically continuous measurements, and percentage is presented for all categorical variables. Comparisons of categorical responses were examined using Fisher's exact test. Means among two or more groups were compared using an analysis of variance (ANOVA). A full ANOVA model was used to compare fixed effects and interactions for age group $(\geq 65$ vs $<65$ ) and current TRT use (yes vs no) for baseline TT and FT levels. A nonparametric Spearman $\rho$ and first order partial correlation coefficient, adjusted for the effect of age, was used to examine the bivariate correlations among parameters. No Bonferroni corrections were used. $P$ values $\leq 0.05$ were considered significant. Any $P$ values below 0.001 are listed as $P<0.001$. All statistical analyses were performed using $\mathrm{SAS}^{\circledR}$ software (version 9.1; SAS Institute, Cary, NC).

\section{Results}

In the United States, 849 men with TD were enrolled in TRiUS at 72 sites. Age was missing for four participants, leaving a study sample of 845 men for the current analysis. Patients were enrolled from March 2008 until December 2008, with the last patient follow-up visit in March 2010. This study focused on the pretreatment characteristics of 133 participants $\geq 65$ years old vs 712 participants $<65$ years old and the treatment outcomes at the 12-month follow-up assessment. The percentage of baseline patients who completed the 12 -month assessment was similar in the $\geq 65(32 \%$; 42/133) and $<65(34 \% ; 242 / 712)$ groups. Patients were recruited primarily from urology physician practices ( $42 \%$ of patients) and endocrine physician practices (37\% of patients), with fewer patients from primary care settings (16\% of patients) or other types of physician practices ( $6 \%$ of patients). Most physicians prescribed either $50 \mathrm{mg}$ testosterone (one $5 \mathrm{-g}$ tube) or $100 \mathrm{mg}$ (two 5-g tubes) of testosterone gel per day, although four patients were prescribed $25 \mathrm{mg} /$ day and three patients were prescribed $75 \mathrm{mg} /$ day at baseline. No patient was prescribed over $100 \mathrm{mg} /$ day. Older patients were prescribed the lower $(\leq 50 \mathrm{mg}$ ) dose of TRT significantly more often; baseline doses were $\leq 50 \mathrm{mg}(86 \%)$ and $100 \mathrm{mg}(14 \%)$ for the $<65$ age group and $\leq 50 \mathrm{mg}(95 \%)$ and $100 \mathrm{mg} \mathrm{(5 \% )}$ for the $\geq 65$ age group $(P=0.004)$.

Table 1 summarizes the baseline demographic and clinical characteristics of patients $\geq 65$ compared with patients $<65$. The $\geq 65$ group had a mean age of $71.7 \pm 5.1$ years and the $<65$ group had a mean age of $48.4 \pm 9.4(P<0.001)$. 
Table I Baseline demographic and clinical characteristics of patients $\geq 65$ vs $<65$ years old

\begin{tabular}{|c|c|c|c|}
\hline & \multicolumn{2}{|l|}{ Baseline, mean \pm SD } & \multirow[t]{2}{*}{$P$ value } \\
\hline & Patients $\geq 65$ & Patients $<65$ & \\
\hline Patients enrolled, $n$ & 133 & 712 & \\
\hline Age, years (range) & $71.7 \pm 5.1(65-84)$ & $48.5 \pm 9.4(20-64)$ & $<0.001$ \\
\hline Total testosterone, $\mathrm{ng} / \mathrm{dL}$ (nmol/L) & $265.0 \pm 108.9(9.2 \pm 3.8)$ & $290.4 \pm 158.3(10.1 \pm 5.5)$ & 0.1 \\
\hline Free testosterone, $\mathrm{pg} / \mathrm{mL}$ (pmol/L) & $46.0 \pm 38.0(159.6 \pm 131.9)$ & $40.0 \pm 65.4(138.8 \pm 226.9)$ & 0.5 \\
\hline $\mathrm{BMI}, \mathrm{kg} / \mathrm{m}^{2}$ & $30.0 \pm 5.4$ & $31.7 \pm 7.1$ & 0.008 \\
\hline PSA, $n g / m L(\mu g / L)$ & $1.82 \pm 1.65(1.82 \pm 1.65)$ & $0.95 \pm 0.86(0.95 \pm 0.86)$ & $<0.001$ \\
\hline \multicolumn{4}{|c|}{ Medical history/current medication use (\%) } \\
\hline Smoking (current or former) & $38 \%$ & $31 \%$ & 0.2 \\
\hline Metabolic syndrome & $39 \%$ & $36 \%$ & 0.6 \\
\hline \multicolumn{4}{|c|}{ (calculated using ATP III definition and baseline data) } \\
\hline Hypertension & $25 \%$ & $19 \%$ & 0.1 \\
\hline Dyslipidemia & $16 \%$ & $21 \%$ & 0.2 \\
\hline Coronary artery disease & $20 \%$ & $17 \%$ & 0.5 \\
\hline Diabetes mellitus & $19 \%$ & $11 \%$ & 0.02 \\
\hline Depression & $5 \%$ & $9 \%$ & 0.2 \\
\hline Sleep disorders (including apnea) & $3 \%$ & $5 \%$ & 0.5 \\
\hline Prior TRT & $23 \%$ & $24 \%$ & 0.9 \\
\hline Current opioid use & $7 \%$ & $11 \%$ & 0.1 \\
\hline Current ED (PDE5 inhibitor use) & $29 \%$ & $18 \%$ & 0.002 \\
\hline Current antidepressant use & 0 & 0 & - \\
\hline
\end{tabular}

Abbreviations: ATP, Adult Treatment Panel; BMI, body mass index; ED, erectile dysfunction; PDE5, phosphodiesterase type 5; PSA, prostate-specific antigen; TRT, testosterone replacement therapy.

The majority of patients were Caucasian (82\%) and were, on mean, obese (mean BMI $30.0 \pm 5.4$ [ $\geq 65$ group] and $31.7 \pm 7.1$ [ $<65$ group]). The most common medical comorbidities included metabolic syndrome, smoking (current or former), hypertension, dyslipidemia, and coronary artery disease. Diabetes mellitus was significantly more common in the $\geq 65$ group ( $19 \%$ vs $11 \% ; P=0.02)$ as was the frequency of current use of a phosphodiesterase type 5 (PDE5) inhibitor for ED ( $29 \%$ vs $18 \% ; P=0.002)$. Patient groups did not differ in their medical history of a diagnosis of depression (5\% vs $9 \% ; P=0.2)$.

The mean duration of TD was a little over 1 year for both groups $(16.7 \pm 31.5$ months for patients $\geq 65$ vs $15.6 \pm 29.7$ months for patients $<65$ [P=0.7]). One patient in the $<65$ group had been hypogonadal for over 252 months (21 years). Most patients were self-referred for TD $(n=75$ among patients $\geq 65 ; \mathrm{n}=455$ among patients $<65$ ), although many were referred from a health care professional $(n=42$, $\mathrm{n}=165$, respectively) or were encouraged to be examined by a spouse or partner $(n=18, n=53$, respectively).

Groups were similar in baseline TT and FT levels (Table 1). The baseline mean serum TT level of patients $\geq 65$ was $265.0 \pm 108.9 \mathrm{ng} / \mathrm{dL}(9.2 \pm 3.8 \mathrm{nmol} / \mathrm{L} ; \mathrm{n}=112)$ compared with $290.4 \pm 158.3 \mathrm{ng} / \mathrm{dL}(10.1 \pm 5.5 \mathrm{nmol} / \mathrm{L} ; \mathrm{n}=611 ; P=0.1)$ among patients $<65$. The mean FT level was $46.0 \pm 38.0 \mathrm{pg} / \mathrm{mL}$ (159.6 $\pm 131.9 \mathrm{pmol} / \mathrm{L} ; \mathrm{n}=68)$ among patients $\geq 65$ compared with $40.0 \pm 65.4 \mathrm{pg} / \mathrm{mL}(138.8 \pm 226.9 \mathrm{pmol} / \mathrm{L} ; \mathrm{n}=393$; $P=0.5$ ) among patients $<65$.

Use of some form of TRT just prior to study enrollment was reported by $23.3 \%$ (31/133) of patients $\geq 65$ and $24.0 \%$ $(171 / 712)$ of patients $<65(P=0.9)$. TRT use prior to study enrollment resulted in higher baseline TT levels in both age groups (Table 2) and was significantly associated with baseline TT levels $(P=0.007)$. There was no statistically significant effect of age group $(P=0.3)$ nor a significant interaction between age group and TRT use $(P=0.9)$ on baseline TT level. For baseline FT there were no statistically significant differences between age groups $(P=0.5)$ or between TRT users and nonusers $(P=0.6)$.

\section{PSA at baseline}

As expected, given the association of higher PSA with older age in the general population, baseline PSA was significantly higher among patients $\geq 65(1.82 \pm 1.65 ; \mathrm{n}=88)$ than patients $<65$ $(0.95 \pm 0.86 ; \mathrm{n}=374 ; P<0.001)$. This was despite patients $\geq 65$ having lower (although not significantly lower) baseline mean serum TT levels than patients $<65$. Baseline TRT use was not significantly associated with differences in baseline PSA levels $(P=0.6)$ nor was there a statistically significant interaction between age and TRT use prior to baseline. At baseline, PSA and TT levels were not significantly correlated (Spearman $\rho$ adjusted for age $=0.08 ; P=0.09 ; \mathrm{n}=450)$. 
Table 2 Baseline total and free testosterone with TRT use prior to enrollment compared with no prior TRT use in patients $\geq 65$ vs $<65$ years old

\begin{tabular}{|c|c|c|c|c|}
\hline & \multicolumn{4}{|l|}{ Mean \pm SD, $n$} \\
\hline & \multicolumn{2}{|l|}{ Patients $\geq 65$} & \multicolumn{2}{|l|}{ Patients $<65$} \\
\hline & Prior TRT & No prior TRT & Prior TRT & No prior TRT \\
\hline \multirow{3}{*}{$\begin{array}{l}\text { Serum TT, ng/dL } \\
\text { (nmol/L) }\end{array}$} & $326.1 \pm 160.8$ & $259.0 \pm 101.6$ & $355.5 \pm 207.1$ & $279.9 \pm 146.5$ \\
\hline & $(11.3 \pm 5.6)$ & $(9.0 \pm 3.5)$ & $(12.3 \pm 7.2)$ & $(9.7 \pm 5.1)$ \\
\hline & $\mathrm{n}=10$ & $\mathrm{n}=102$ & $\mathrm{n}=85$ & $n=526$ \\
\hline & $34.3 \pm 28.2$ & $47.3 \pm 38.9$ & $61.4 \pm 67.6$ & $36.0 \pm 64.4$ \\
\hline \multirow[t]{2}{*}{ (pmol/L) } & $(119.0 \pm 97.9)$ & $(164.1 \pm 135.0)$ & $(213.1 \pm 234.6)$ & $(124.9 \pm 223.5)$ \\
\hline & $\mathrm{n}=7$ & $\mathrm{n}=6 \mathrm{I}$ & $\mathrm{n}=6 \mathrm{I}$ & $\mathrm{n}=332$ \\
\hline
\end{tabular}

Abbreviations: FT, free testosterone; SD, standard deviation; TRT, testosterone replacement therapy; TT, total testosterone.

\section{Baseline correlations}

At baseline, prior to TRT, there were statistically significant $(P<0.001)$ correlations (Spearman $\rho$ adjusted for age ranged from -0.14 to -0.21 ) between TT levels in the entire group and diastolic BP and anthropometric measures (ie, weight, BMI, waist circumference, and hip circumference) (Table 3). Similar associations were not found for FT, PSA, or sex hormone-binding globulin (SHBG). Plasma glucose levels significantly and negatively correlated with both TT $(\rho=-0.15 ; \mathrm{n}=354 ; P=0.004)$ and FT $(\rho=-0.15$; $\mathrm{n}=248 ; P=0.02)$. No testosterone-related parameters correlated with total cholesterol, HDL or LDL cholesterol, or triglycerides.

\section{2-month follow-up}

Approximately $33 \%$ of patients in both the $\geq 65$ and $<65$ age groups at baseline completed the 12-month assessment. Patient-reported compliance with TRT dosing (total days/length on TRT) using diary cards did not significantly differ between patients $\geq 65$ (91.2\% compliance; $\mathrm{n}=76$ ) and patients $<65(91.7 \%$ compliance; $\mathrm{n}=394 ; P>0.7)$ at 12-month follow-up.

At the 12-month follow-up, TT levels significantly increased from baseline in both age groups (Table 4).
FT levels also increased from baseline, although the increase did not reach significance in the group of patients $\geq 65$. Mean TT and FT levels did not significantly differ between age groups at 12-month follow-up (Table 5). There was no significant difference between age groups in the percentage of patients using $100 \mathrm{mg}$ of TRT at 12-month follow-up ( $\leq 50 \mathrm{mg}$ dosing: $74 \%$ of patients $\geq 65,67 \%$ of patients $<65$; $100 \mathrm{mg}$ dosing: $26 \%$ of patients $\geq 65,33 \%$ of patients $<65$; $P=0.5)$. However, the lack of significant difference should be interpreted with caution given the small sample size of patients $\geq 65$ receiving $100 \mathrm{mg}$ dosing (ten patients).

At 12 months, PSA levels did not significantly differ between patients $\geq 65(2.18 \pm 2.18 \mathrm{ng} / \mathrm{mL}[2.18 \pm 2.18 \mu \mathrm{g} / \mathrm{L}]$; $\mathrm{n}=20)$ compared with patients $<65(1.14 \pm 0.84 \mathrm{ng} / \mathrm{mL}$ $[1.14 \pm 0.84 \mu \mathrm{g} / \mathrm{L}] ; \mathrm{n}=69, P=0.1$, see Table 4). PSA levels did not significantly increase from baseline to follow-up in patients $\geq 65(0.33 \pm 1.57 \mathrm{ng} / \mathrm{mL}[0.33 \pm 1.57 \mu \mathrm{g} / \mathrm{L}]$ increase; $\mathrm{n}=20 ; P=0.4)$. PSA levels did significantly increase in patients $<65(0.17 \pm 0.58 \mathrm{ng} / \mathrm{mL}[0.17 \pm 0.58 \mu \mathrm{g} / \mathrm{L}]$ increase; $\mathrm{n}=69 ; P=0.01)$. The difference in statistical significance is due to the difference in sample sizes of patients with both baseline and 12-month follow-up PSA measurements among the two cohorts and also due to the large SD in the change in PSA among patients in the older cohort.

Table 3 Baseline first-order Spearman $\rho$ partial correlations for the entire study group

\begin{tabular}{lllll}
\hline & \multicolumn{2}{l}{ Spearman $\rho, P$ value } & & \\
\cline { 2 - 5 } & TT & FT & PSA & SHBG \\
\hline $\mathrm{n}$ & 708 & 450 & 454 & 127 \\
Weight & $-0.19, P<0.001$ & $-0.04, P=0.4$ & $-0.05, P=0.3$ & $-0.07, P=0.4$ \\
BMI & $-0.21, P<0.001$ & $-0.07, P=0.2$ & $-0.06, P=0.2$ & $-0.09, P=0.3$ \\
Waist circumference & $-0.16, P<0.001$ & $-0.07, P=0.1$ & $-0.04, P=0.5$ & $-0.01, P=0.9$ \\
Hip circumference & $-0.14, P<0.001$ & $-0.07, P=0.1$ & $-0.04, P=0.4$ & $-0.02, P=0.8$ \\
SBP & $-0.07, P=0.06$ & $0.04, P=0.4$ & $-0.01, P=0.8$ & $0.11, P=0.2$ \\
DBP & $-0.16, P<0.001$ & $-0.14, P=0.004$ & $-0.02, P=0.7$ & $0.11, P=0.2$ \\
\hline
\end{tabular}

Abbreviations: BMI, body mass index; DBP, diastolic blood pressure; FT, free testosterone; PSA, prostate-specific antigen; SBP, systolic blood pressure; SHBG, sex hormone-binding globulin; TT, total testosterone. 
Table 4 Change from baseline to I2-month follow-up in testosterone and PSA in patients $\geq 65$ vs $<65$ years old

\begin{tabular}{|c|c|c|c|c|}
\hline & \multicolumn{4}{|c|}{ Mean $\pm S D, n, P$ value for change from baseline } \\
\hline & \multicolumn{2}{|l|}{ Patients $\geq 65$} & \multicolumn{2}{|l|}{ Patients $<65$} \\
\hline & $\begin{array}{l}\text { Month } 12 \\
\text { measurement }\end{array}$ & $\begin{array}{l}\text { Change from } \\
\text { baseline }\end{array}$ & $\begin{array}{l}\text { Month I2 } \\
\text { measurement }\end{array}$ & $\begin{array}{l}\text { Change from } \\
\text { baseline }\end{array}$ \\
\hline Serum TT, ng/dL & $524.0 \pm 393.7$ & $229.7 \pm 454.1$ & $491.1 \pm 201.8$ & $232.9 \pm 230.2$ \\
\hline \multirow[t]{2}{*}{$(\mathrm{nmol} / \mathrm{L})$} & $(18.2 \pm 13.7)$ & $(8.0 \pm 15.8)$ & $(I 7.0 \pm 7.0)$ & $(8.1 \pm 8.0)$ \\
\hline & $n=24$ & $\mathrm{n}=23,{ }^{\mathrm{a}} \mathrm{P}=0.02$ & $\mathrm{n}=126,{ }^{b} \mathrm{P}=0.5$ & $\mathrm{n}=114,{ }^{\mathrm{a}} \mathrm{P}<0.00 \mathrm{I}$ \\
\hline $\mathrm{FT}, \mathrm{pg} / \mathrm{mL}$ & $95.2 \pm 163.4$ & $15.4 \pm 72.8$ & $65.5 \pm 61.8$ & $27.7 \pm 88.8$ \\
\hline \multirow[t]{2}{*}{ (pmol/L) } & $(330.3 \pm 567.0)$ & $(53.4 \pm 252.6)$ & $(227.3 \pm 214.4)$ & $(96.1 \pm 308.1)$ \\
\hline & $\mathrm{n}=16$ & $\mathrm{n}=12,{ }^{\mathrm{a}} \mathrm{P}=0.5$ & $\mathrm{n}=94,{ }^{\mathrm{b}} \mathrm{P}=0.2$ & $\mathrm{n}=70,{ }^{\mathrm{a}} P=0.01$ \\
\hline PSA, ng/mL & $2.18 \pm 2.18$ & $0.33 \pm 1.57$ & $1.14 \pm 0.84$ & $0.17 \pm 0.58$ \\
\hline \multirow[t]{2}{*}{$(\mu g / L)$} & $(2.18 \pm 2.18)$ & $(0.33 \pm 1.57)$ & $(1.14 \pm 0.84)$ & $(0.17 \pm 0.58)$ \\
\hline & $\mathrm{n}=20$ & $\mathrm{n}=20,{ }^{\mathrm{a}} \mathrm{P}=0.4$ & $\mathrm{n}=69,{ }^{b} \mathrm{P}=0.1$ & $\mathrm{n}=69,{ }^{\mathrm{a}} P=0.01$ \\
\hline
\end{tabular}

Notes: ${ }^{\text {aCCmpared }}$ with baseline; ' compared with patients $\geq 65$ years old.

Abbreviations: FT, free testosterone; PSA, prostate-specific antigen; TT, total testosterone.

Over the course of the 12-month study, eleven patients in the $\geq 65$ group and six patients in the $<65$ group showed a PSA level $>4.0 \mathrm{ng} / \mathrm{mL}(>4.0 \mu \mathrm{g} / \mathrm{L})$ or an increase in PSA over baseline of $>1.4 \mathrm{ng} / \mathrm{mL}(>1.4 \mu \mathrm{g} / \mathrm{L})$.

Twenty adverse events were reported in 568 patients during the course of 1259 postbaseline visits. Skin rash and itching were reported in six and two patients, respectively. Events occurring in one patient each included bad odor, nasopharyngitis, weight gain, perianal burning, dizziness, "not obvious hypogonadal," redness, skin allergy, prostate cancer, increased lipid panel, and elevated PSA. One patient died after having surgery for an arteriovenous malformation resection; the death was secondary to complications of the resection in the region of patient's pituitary and not considered related to TRT or treatment with Testim.

\section{Correlations among 12-month changes in parameters}

There was a statistically significant correlation between the change in TT from baseline at 12 months with the change in waist circumference. As TT increased, waist circumference decreased (Table 5). There were no other statistically significant correlations between changes in TT, FT, PSA, and SHBG with changes in anthropometrics or BP.

The change in TT was significantly correlated with the change in plasma glucose levels $(\rho=-0.29 ; \mathrm{n}=61 ; P=0.03)$ but was not correlated with changes in total cholesterol, HDL or LDL cholesterol, or triglycerides. The change in FT was significantly correlated with changes in total cholesterol $(\rho=-0.32 ; P=0.03 ; \mathrm{n}=46)$ and LDL cholesterol $(\rho=-0.32$; $P=0.03 ; \mathrm{n}=46)$ but was not correlated with changes in glucose, HDL cholesterol, or triglycerides.

\section{Age 75 and older}

Secondary analyses examined baseline differences among three levels of age; participants age 65-74 years $(n=102)$, participants $\geq 75$ years $(n=31)$, and participants $<65(n=712)$ at baseline. The mean duration of TD did not significantly differ among the three age cohorts ( $\geq 75$ years, $12.9 \pm 27.0$ months; 65-74 years, $17.9 \pm 32.7$ months; $<65$ years, $15.6 \pm 29.7$; $P=0.6)$. Patient-reported compliance at 12-month follow-up based on diary cards did not significantly differ between patients $65-74$ years old $(91.0 \% ; n=54)$ compared with patients $\geq 75$ years $(91.7 \% ; \mathrm{n}=22)$ or patients $<65$ years $(91.7 \% ; \mathrm{n}=394)(P=0.9)$.

The three age cohorts were similar in baseline TT and FT levels. The baseline mean serum TT level of patients $65-74$ years was $269.3 \pm 113.0 \mathrm{ng} / \mathrm{dL}(9.3 \pm 3.9 \mathrm{nmol} / \mathrm{L}$; $\mathrm{n}=86)$ compared with $251.0 \pm 94.3 \mathrm{ng} / \mathrm{dL}(8.7 \pm 3.3 \mathrm{nmol} / \mathrm{L})$ among patients $\geq 75(\mathrm{n}=26)$ and $290.4 \pm 158.3 \mathrm{ng} /$ $\mathrm{dL}(10.1 \pm 5.5 \mathrm{nmol} / \mathrm{L})$ among patients $<65$

Table 5 Spearman $\rho$ partial correlations of the change in parameters from baseline to 12 -month follow-up in the entire study group

\begin{tabular}{llll}
\hline \multicolumn{4}{l}{ Spearman $\rho, P$ value } \\
\cline { 2 - 4 } & TT & FT & PSA \\
\hline $\mathrm{n}$ & 126 & 75 & 84 \\
Weight & $-0.15, P=0.1$ & $-0.01, P=0.9$ & $-0.09, P=0.4$ \\
BMI & $-0.15, P=0.1$ & $-0.01, P=0.9$ & $-0.10, P=0.4$ \\
Waist circumference & $-0.23, P=0.01$ & $-0.10, P=0.4$ & $-0.05, P=0.6$ \\
Hip circumference & $-0.15, P=0.1$ & $-0.06, P=0.6$ & $-0.07, P=0.5$ \\
SBP & $-0.03, P=0.7$ & $0.004, P=0.9$ & $-0.02, P=0.8$ \\
DBP & $0.01, P=0.9$ & $0.11, P=0.3$ & $-0.10, P=0.4$ \\
\hline
\end{tabular}

Abbreviations: BMI, body mass index; DBP, diastolic blood pressure; $F T$, free testosterone; PSA, prostate-specific antigen; SBP, systolic blood pressure; TT, total testosterone. 
$(\mathrm{n}=611)(P=0.2)$. The mean FT level of patients $65-74$ years was $47.8 \pm 40.7 \mathrm{pg} / \mathrm{mL}(165.9 \pm 141.2 \mathrm{pmol} / \mathrm{L} ; \mathrm{n}=49)$ compared with $41.1 \pm 30.2 \mathrm{pg} / \mathrm{mL}(142.6 \pm 104.8 \mathrm{pmol} / \mathrm{L})$ among patients $\geq 75(\mathrm{n}=19)$ and $40.0 \pm 65.4 \mathrm{pg} / \mathrm{mL}$ $(138.8 \pm 226.9 \mathrm{pmol} / \mathrm{L})$ among patients $<65(\mathrm{n}=393)$ $(P=0.7)$.

\section{Discussion}

The age group typically examined for late onset hypogonadism extends into middle adulthood (age 50 years and older), and testosterone replacement therapy studies focused on older adult ( $\geq 65$ years) hypogonadal patients are limited. Available studies of hypogonadal men $\geq 50$ years old suggest that TRT may be effective in alleviating symptoms among patients in this age group. ${ }^{28-32}$ Among healthy men $\geq 60$ years old, TRT has been associated with increased lean body mass, decreased fat mass, and increased muscle strength. ${ }^{33-35}$ Testim, the drug used in the current study, has previously been shown to be effective in two 90-day, randomized, placebo-controlled studies, demonstrating improvements in mean concentrations of testosterone, sexual function, lean body mass, and percentage of body fat among men 20-80 years old, ${ }^{36,37}$ which were maintained to 12 months. ${ }^{38}$ In the current study examining the effect of TRT in older men, we observed similar improvements after TRT, irrespective of age, suggesting that hypogonadal men $\geq 65$ years may find benefit with careful monitoring.

In the current study, hypogonadal men $\geq 65$ years old and enrolled in TRiUS comprised $16 \%$ of the registry participants. This percentage of patients could be seen as high given the debate about treating older adults with TD ${ }^{18}$ Alternatively, the treatment rate appears quite low given that men $\geq 65$ years attending primary care practices throughout the US were 1.2 times more likely to present with hypogonadism than men younger than 65 years. ${ }^{5}$ The current study findings demonstrated that men $\geq 65$ years were similar to men $<65$ years in the duration of TD prior to study enrollment (a little longer than 1 year), prior use of TRT ( $10 \%$ and $14 \%$, respectively), TT and FT levels at baseline, TT and FT levels at 12-month follow-up, and in their reported compliance with treatment. TRT dose was not controlled and TRT dose titration over the 12-month study period was unknown; thus, only baseline and 12-month TRT dose were reported. Patients $\geq 65$ years were prescribed a lower dose of TRT at baseline significantly more often (95\%) than patients $<65$ years $(86 \%)$. Although the percentage of patients using $50 \mathrm{mg}$ vs $100 \mathrm{mg}$ testosterone dosing at 12-month follow-up did not significantly differ between age groups (100 mg: $26 \%$ of patients $\geq 65,33 \%$ of patients $<65$ ), the lack of significant difference should be interpreted with caution given the small sample sizes. The data show that no patient was prescribed over $100 \mathrm{mg}$ /day and suggest that older patients were more likely to continue to receive the lower TRT dose.

Both age groups showed a significant increase in TT levels at 12 months (which fell within the range suggested by the Endocrine Society), ${ }^{6}$ with mean TT at approximately 524 and $491 \mathrm{ng} / \mathrm{dL}(18.2$ and $17.0 \mathrm{nmol} / \mathrm{L})$, respectively, demonstrating a significant response to TRT independent of age. Thus, on average, older aged patients receiving 50 or $100 \mathrm{mg}$ /day TRT attained a TT level within the physiological range that is considered optimal, between 400 and $800 \mathrm{ng} / \mathrm{dL}$ (13.9 and $27.8 \mathrm{nmol} / \mathrm{L})^{6,9}$ following TRT. Importantly, treatment in older patients did not lead to attainment of supraphysiologic TT levels following TRT use of $50 \mathrm{mg}$ or $100 \mathrm{mg} /$ day. Although FT levels did increase over the 12-month treatment period, the increase was not significant in the group of patients $\geq 65$. The lack of significance may be the result of a small sample size of patients undergoing FT testing at 12 months among the older patients, and the consequent lack of statistical power. Notably, the FT levels at 12 months did not significantly differ between patients $\geq 65$ and $<65$ years.

The oldest participants ( $\geq 75$ years) had similar duration of TD, similar TT and FT levels at baseline, and similar compliance with treatment when compared with participants who were $65-74$ and $<65$ years. The current study was unable to compare responses to TRT at 12 months between participants $\geq 75$ years and those younger due to limited number of participants in the $\geq 75$ group with TT and FT testing at 12-month follow-up. Consequently, it is not known whether the response to TRT declined among the oldest patients. However, similar TT and FT levels at baseline and sustained high levels of treatment compliance across all of the age groups supports the likelihood of an adequate response to TRT among the oldest participants.

TRT in older hypogonadal men requires consideration of the risks and benefits of TRT ${ }^{6}$ and in particular the possibility of an increased risk in rate of prostate events, such as PSA levels $>4 \mathrm{ng} / \mathrm{mL}(>4 \mu \mathrm{g} / \mathrm{L})$, prostate biopsies, and prostate cancer. ${ }^{39}$ In the current study, the oldest group of patients $(\geq 75)$ showed the highest PSA levels at baseline, and patients $\geq 65$ had a significantly higher mean PSA level than the $<65$ group at baseline and at 12-month follow-up. However, the $\geq 65$ group did not show significantly increased PSA at 12 months compared with baseline, whereas the $<65$ group did. The mean increase in PSA 
level among patients $\geq 65$ years in the current study was $0.33 \mathrm{ng} / \mathrm{mL}(0.33 \mu \mathrm{g} / \mathrm{L})$ and among patients $<65$ years was $0.17 \mathrm{ng} / \mathrm{mL}(0.17 \mu \mathrm{g} / \mathrm{L})$. These mean increases are consistent with what has been previously found in PSA level change following TRT; approximately $0.30 \mathrm{ng} / \mathrm{mL}$ $(0.30 \mu \mathrm{g} / \mathrm{L})$ overall and $0.43 \mathrm{ng} / \mathrm{mL}(0.43 \mu \mathrm{g} / \mathrm{L})$ among older men on average. ${ }^{40}$ PSA level increases associated with TRT typically occur during the initial 6 months of treatment, ${ }^{27}$ and further PSA level changes are considered age-related changes in PSA levels. ${ }^{40}$ The mean PSA level of $2.18 \mathrm{ng} / \mathrm{mL}$ $(2.18 \mu \mathrm{g} / \mathrm{L})$ at 12 -month follow-up among the patients $\geq 65$ years is consistent with a study examining age-stratified normal values for PSA level; mean PSA levels increased with aging from 1.1 to $2.5 \mathrm{ng} / \mathrm{mL}$ ( 1.1 to $2.5 \mu \mathrm{g} / \mathrm{L}$ ) among community-dwelling men $50-80$ years old ${ }^{41}$ Consistent with the prostate saturation theory in which PSA and prostate tissue growth are sensitive to changes in serum testosterone only when serum testosterone levels are low, clinicians may expect an initial increase in PSA in hypogonadal men following TRT during the first few months. ${ }^{27}$ Increases in PSA levels during the first year of TRT that are $>1.4 \mathrm{ng} / \mathrm{mL}$ $(1.4 \mu \mathrm{g} / \mathrm{L})^{6}$ or PSA levels $>4 \mathrm{ng} / \mathrm{mL}(4 \mu \mathrm{g} / \mathrm{L})^{40}$ may be unusual and suggest the need for a urological consultation as per the Endocrine Society guidelines. ${ }^{6}$ In the current study, a small number of patients (eleven patients $\geq 65$ years; six patients $<65$ years) had a PSA level $>4 \mathrm{ng} / \mathrm{mL}(4 \mu \mathrm{g} / \mathrm{L})$ or an increase in PSA $>1.4 \mathrm{ng} / \mathrm{mL}(1.4 \mu \mathrm{g} / \mathrm{L})$ at some time during the 12-month study period.

Although the TRiUS registry was not specifically designed to assess safety, adverse event reporting suggests TRT was well tolerated in both age groups. Additionally, study findings suggest that cardiovascular risk factors did not worsen during 12 months of TRT in men $\geq 65$ years. This was a concern given the results of a recent trial examining the effect of Testim on muscle strength and physical performance in a population of community-dwelling men $\geq 65$ years old with limitations in mobility and a high prevalence of cardiovascular risk factors (ie, hypertension, diabetes, hyperlipidemia, and obesity). ${ }^{18}$ The trial was halted due to a higher rate of cardiovascular-related adverse events in the TRT group compared with placebo. However, the trial design limits generalizing these findings to a larger population, given the small size of the trial, the initial high dose of TRT used, and the unique mobility-limited population. A recent review examining the cardiovascular risk of TRT in elderly males concluded that TRT does not increase cardiovascular risk or adversely affect the cardiovascular profile in older men. ${ }^{42}$
The current study found associations between lower TT levels and cardiovascular risk factors of greater weight, BMI, waist and hip circumference, diastolic BP, and plasma glucose levels at baseline, independent of age. TT levels at baseline were not associated with total cholesterol, HDL, LDL, or triglycerides. Lower FT levels at baseline were associated with greater plasma glucose levels independent of age but not with anthropometric or cardiovascular factors. Average BMI at baseline did not significantly differ between age groups and was in the obese range. Whether obesity may serve as a potential indicator of TD in older men is not yet known, and no published study as yet, has specifically addressed differences in BMI in older men without TD compared with older men with TD.

Over the 12 months of the study, increase in TT level was associated with decreased waist circumference and plasma glucose levels and increase in FT level was associated with decreased total and LDL cholesterol, independent of age. Notably, the percentage of patients completing follow-up assessments was similar between men $\geq 65$ and men $<65$ at 12 months, indicating there was not a disproportionate loss to follow-up based on age.

It has been suggested that aging of men in the US will cause a large increase in the burden of TD, with an estimated prevalence of symptomatic TD of 6.5 million by the year 2025 among American men 30-79 years of age. ${ }^{4}$ The primary care setting seems an ideal place for testosterone level testing and TD screening. However, in the primary care setting, barriers to diagnosis of TD and referral to treatment include lack of physician-patient communication, inadequate provider knowledge or assessment tools, as well as personal, cultural, or gender influences. ${ }^{43}$ Increased clinician awareness that older men with TD may present with symptoms that are easily misinterpreted as signs of aging or chronic disease is needed as well as an understanding that older men with TD show benefit from TRT. Prior studies have shown the benefits of TRT on visceral fat, total body fat-free mass, and total body and thigh skeletal muscle mass among healthy older hypogonadal men; ${ }^{30,31,44}$ benefits have also been shown on insulin resistance, improved glycemic control, and improved visceral adiposity among older hypogonadal men with type 2 diabetes, ${ }^{45}$ on symptoms of metabolic syndrome, ${ }^{28}$ and on symptoms of depression among older hypogonadal men with dysthymia or minor depression. ${ }^{32}$ However, these positive results must be tempered by the lack of long-term efficacy and safety studies of TRT in hypogonadal men of all ages; while older men with TD may expect benefit from TRT, they must be carefully monitored during treatment. 
The limitations to our study are characteristic of patient registries where, unlike placebo-controlled studies, physician and patient behavior are not directed. There was a high degree of variability in inter-patient data collection, no standardized definition of TD, no testosterone washout period before enrollment, no centralized laboratory testing facility, and no standardized time of testosterone draw. The differences between the primary age groups in enrollment sample size, although expected given that the study is not a controlled trial, may have influenced statistical analyses. Also, patient-supplied records were the evidence used for drug compliance.

\section{Conclusion}

The current study adds to the body of literature on TRT among men $\geq 65$ years old by providing longitudinal data on TRT with $50 \mathrm{mg}$ and $100 \mathrm{mg} /$ day of Testim among older men from diverse clinical settings. Hypogonadal men $\geq 65$ showed significant benefit from TRT over 12 months that was similar to the response of hypogonadal men $<65$. TRT was well tolerated in older patients, successfully increased testosterone level regardless of age, and did not significantly increase PSA levels in older men.

\section{Acknowledgments}

Funding to support this study and the preparation of this manuscript was provided by Auxilium Pharmaceuticals. An Auxilium employee co-authored this paper and was involved in the study design, analysis and interpretation of data, writing of the report, and final approval to submit. The authors thank Lynanne McGuire, PhD, of MedVal Scientific Information Services, LLC, for providing medical writing and editorial assistance. This manuscript was prepared according to the International Society for Medical Publication Professionals "Good publication practice for communicating companysponsored medical research: the GPP2 Guidelines."

\section{Disclosure}

RKB - Advisor/consultant: Auxilium. Speaker: Abbott, Bristol-Myers Squibb, Novartis, Sanofi-Aventis. MK Research funding: Allergan. Advisor/consultant: Meda. Speaker: Auxilium, Slate. GB - Research funding: Auxilium, Boehringer Ingelheim, Gilead, Pfizer, Sangamo, ViiV. Advisor/consultant: Auxilium, Bristol-Myers Squibb, Merck, Tibotec, ViiV. Speaker: Abbott, Auxilium, Boehringer Ingelheim, Bristol-Myers Squibb, Merck, Tibotec, ViiV. HK - Employee: Auxilium. MMM - Board membership: Sexual Medicine Society of North America.
Research funding: Auxilium, GlaxoSmithKline. Advisor/ consultant: Abbott, Auxilium, Endo. All authors contributed equally and were involved in study design, data acquisition, or data analysis/interpretation and in drafting and/or critically revising the manuscript. All authors reviewed the final manuscript and gave approval for submission.

\section{References}

1. Araujo AB, O’Donnell AB, Brambilla DJ, et al. Prevalence and incidence of androgen deficiency in middle-aged and older men: estimates from the Massachusetts Male Aging Study. J Clin Endocrinol Metab. 2004;89:5920-5926.

2. Harman SM, Metter EJ, Tobin JD, Pearson J, Blackman MR Longitudinal effects of aging on serum total and free testosterone levels in healthy men. Baltimore Longitudinal Study of Aging. J Clin Endocrinol Metab. 2001;86:724-731.

3. Travison TG, Araujo AB, Kupelian V, O’Donnell AB, McKinlay JB. The relative contributions of aging, health, and lifestyle factors to serum testosterone decline in men. J Clin Endocrinol Metab. 2007;92: 549-555.

4. Araujo AB, Esche GR, Kupelian V, et al. Prevalence of symptomatic androgen deficiency in men. J Clin Endocrinol Metab. 2007;92: 4241-4247.

5. Mulligan T, Frick MF, Zuraw QC, Stemhagen A, McWhirter C. Prevalence of hypogonadism in males aged at least 45 years: the HIM study. Int J Clin Pract. 2006;60:762-769.

6. Bhasin S, Cunningham GR, Hayes FJ, et al. Testosterone therapy in men with androgen deficiency syndromes: an Endocrine Society clinical practice guideline. J Clin Endocrinol Metab. 2010;95:2536-2559.

7. Laaksonen DE, Niskanen L, Punnonen K, et al. Testosterone and sex hormone-binding globulin predict the metabolic syndrome and diabetes in middle-aged men. Diabetes Care. 2004;27:1036-1041.

8. Traish AM, Saad F, Feeley RJ, Guay AT. The dark side of testosterone deficiency: III. Cardiovascular disease. J Andol. 2009;30:477-494.

9. AACE Hypogonadism Task Force. American Association of Clinical Endocrinologists medical guidelines for clinical practice for the evaluation and treatment of hypogonadism in adult male patients - 2002 update. Endocr Pract. 2002;8:439-456.

10. Shores MM, Sloan KL, Matsumoto AM, Moceri VM, Felker B, Kivlahan DR. Increased incidence of diagnosed depressive illness in hypogonadal older men. Arch Gen Psychiatry. 2004;61:162-167.

11. Kapoor D, Jones TH. Androgen deficiency as a predictor of metabolic syndrome in aging men: an opportunity for intervention? Drugs Aging. 2008;25:357-369.

12. Tuck SP, Francis RM. Testosterone, bone and osteoporosis. Front Horm Res. 2009;37:123-132.

13. Szulc P, Claustrat B, Marchand F, Delmas PD. Increased risk of falls and increased bone resorption in elderly men with partial androgen deficiency: the MINOS study. J Clin Endocrinol Metab. 2003;88:5240-5247.

14. Auyeung TW, Lee JS, Kwok T, et al. Testosterone but not estradiol level is positively related to muscle strength and physical performance independent of muscle mass: a cross-sectional study in 1489 older men. Eur J Endocrinol. 2011;164:811-817.

15. Maggio M, Ceda GP, Lauretani F, et al. Gonadal status and physical performance in older men. Aging Male. 2011;14:42-47.

16. Schaap LA, Pluijm SM, Smit JH, et al. The association of sex hormone levels with poor mobility, low muscle strength and incidence of falls among older men and women. Clin Endocrinol. 2005;63:152-160.

17. Orwoll E, Lambert LC, Marshall LM, et al. Endogenous testosterone levels, physical performance, and fall risk in older men. Arch Intern Med. 2006;166:2124-2131.

18. Basaria S, Coviello AD, Travison TG, et al. Adverse events associated with testosterone administration. N Engl J Med. 2010;363:109-122. 
19. Jones T. Clinical awareness and diagnosis of male hypogonadism. J Men's Health. 2009;5:S26-S34.

20. Miner MM, Khera M, Bhattacharya R, Blick G, Kushner H. Baseline data from the TRiUS registry: symptoms and comorbidities of testosterone deficiency. Postgrad Med. 2011;123:17-27.

21. Khera M, Bhattacharya RK, Blick G, Kushner H, Nguyen D, Miner MM. Improved sexual function with testosterone replacement therapy in hypogonadal men: real-world data from the Testim Registry in the US (TRiUS). J Sex Med. 2011;8:3204-3213.

22. Khera M, Bhattacharya RK, Blick G, Kushner H, Nguyen D, Martin MM. The effect of testosterone supplementation on depression symptoms in hypogonadal men from the Testim Registry in the US (TRiUS). Aging Male. 2012;15:14-21.

23. Blick G, Khera M, Bhattacharya RK, Nguyen D, Kushner H, Miner MM. Testosterone replacement therapy outcomes among opioid users: the Testim Registry in the United States (TRiUS). Pain Med. 2012;13: 688-698.

24. Blick G, Miner MM, Khera M, Bhattacharya RK, Kushner H, Nguyen D. Testim Registry in the United States (TRiUS): baseline demographic and clinical parameters for HIV/AIDS patients with hypogonadism. Presented at: International Association of Physicians in AIDS Care, November 29-December 1, 2009, New Orleans, LA.

25. Blick G, Khera M, Miner M, Bhattacharya R, Kushner H, Nguyen D. Effect of testosterone replacement therapy (TRT) on sexual function, depression, and BMI in hypogonadal men with HIV/AIDS: analysis of a sub-cohort of the Testim Registry in United States (TRiUS). Presented at: XVIII International AIDS Conference (AIDS 2010), July 18-23, 2010, Vienna, Austria.

26. Bhattacharya RK, Khera M, Blick G, Kushner H, Nguyen D, Miner MM. Effect of 12 months of testosterone replacement therapy on metabolic syndrome components in hypogonadal men: data from the Testim Registry in the US (TRiUS). BMC Endocr Disord. 2011;11:18.

27. Khera M, Bhattacharya RK, Blick G, Kushner H, Nguyen D, Miner MM. Changes in prostate specific antigen in hypogonadal men after 12 months of testosterone replacement therapy: support for the prostate saturation theory. J Urol. 2011;186:1005-1011.

28. Permpongkosol S, Tantirangsee N, Ratana-Olarn K. Treatment of 161 men with symptomatic late onset hypogonadism with long-acting parenteral testosterone undecanoate: effects on body composition, lipids, and psychosexual complaints. J Sex Med. 2010;7:3765-3774.

29. Kenny AM, Kleppinger A, Annis K, et al. Effects of transdermal testosterone on bone and muscle in older men with low bioavailable testosterone levels, low bone mass, and physical frailty. J Am Geriatr Soc. 2010;58:1134-1143.

30. Allan CA, Strauss BJ, Burger HG, Forbes EA, McLachlan RI. Testosterone therapy prevents gain in visceral adipose tissue and loss of skeletal muscle in nonobese aging men. J Clin Endocrinol Metab. 2008;93:139-146.

31. Ottenbacher KJ, Ottenbacher ME, Ottenbacher AJ, Acha AA, Ostir GV. Androgen treatment and muscle strength in elderly men: A metaanalysis. J Am Geriatr Soc. 2006;54:1666-1673.

32. Shores MM, Kivlahan DR, Sadak TI, Li EJ, Matsumoto AM. A randomized, double-blind, placebo-controlled study of testosterone treatment in hypogonadal older men with subthreshold depression (dysthymia or minor depression). J Clin Psychiatry. 2009;70:1009-1016.
33. Emmelot-Vonk MH, Verhaar HJ, Nakhai Pour HR, et al. Effect of testosterone supplementation on functional mobility, cognition, and other parameters in older men: a randomized controlled trial. JAMA. 2008;299:39-52.

34. Ferrando AA, Sheffield-Moore M, Yeckel CW, et al. Testosterone administration to older men improves muscle function: molecular and physiological mechanisms. Am J Physiol Endocrinol Metab. 2002;282:E601-E607.

35. Srinivas-Shankar U, Roberts SA, Connolly MJ, et al. Effects of testosterone on muscle strength, physical function, body composition, and quality of life in intermediate-frail and frail elderly men: a randomized, double-blind, placebo-controlled study. J Clin Endocrinol Metab. 2010;95:639-650.

36. Steidle C, Schwartz S, Jacoby K, Sebree T, Smith T, Bachand R. AA2500 testosterone gel normalizes androgen levels in aging males with improvements in body composition and sexual function. J Clin Endocrinol Metab. 2003;88:2673-2681.

37. McNicholas TA, Dean JD, Mulder H, Carnegie C, Jones NA. A novel testosterone gel formulation normalizes androgen levels in hypogonadal men, with improvements in body composition and sexual function. $B J U$ Int. 2003;91:69-74.

38. Dean JD, Carnegie C, Rodzvilla J, Smith T. Long-term effects of Testim ${ }^{\circledR}$ $1 \%$ testosterone gel in hypogonadal men. Rev Urol. 2005;7:87-94.

39. Calof OM, Singh AB, Lee ML, et al. Adverse events associated with testosterone replacement in middle-aged and older men: a meta-analysis of randomized, placebo-controlled trials. J Gerontol A Biol Sci Med Sci. 2005;60:1451-1457.

40. Bhasin S, Singh AB, Mac RP, Carter B, Lee MI, Cunningham GR. Managing the risks of prostate disease during testosterone replacement therapy in older men: recommendations for a standardized monitoring plan. J Andol. 2003;24:299-311.

41. Berges R, Oelke M. Age-stratified normal values for prostate volume, PSA, maximum urinary flow rate, IPSS, and other LUTS/BPH indicators in the German male community-dwelling population aged 50 years or older. World J Urol. 2011;29:171-178.

42. Carson CC III, Rosano G. Exogenous testosterone, cardiovascular events, and cardiovascular risk factors in elderly men: a review of trial data. J Sex Med. 2012;9:54-67.

43. Rice D, Brannigan RE, Campbell RK, et al. Men's health, low testosterone, and diabetes: individualized treatment and a multidisciplinary approach. Diabetes Educ. 2008;34(Suppl 5):97S-112S.

44. Wittert GA, Chapman IM, Haren MT, Mackintosh S, Coates P, Morley JE. Oral testosterone supplementation increases muscle and decreases fat mass in healthy elderly males with low-normal gonadal status. J Gerontol A Biol Sci Med Sci. 2003;58:618-625.

45. Kapoor D, Goodwin E, Channer KS, Jones TH. Testosterone replacement therapy improves insulin resistance, glycaemic control, visceral adiposity and hypercholesterolaemia in hypogonadal men with type 2 diabetes. Eur J Endocrinol. 2006;154:899-906.
Clinical Interventions in Aging

\section{Publish your work in this journal}

Clinical Interventions in Aging is an international, peer-reviewed journal focusing on evidence-based reports on the value or lack thereof of treatments intended to prevent or delay the onset of maladaptive correlates of aging in human beings. This journal is indexed on PubMed Central, MedLine, the American Chemical Society's 'Chemical Abstracts Ser-

\section{Dovepress}

vice' (CAS), Scopus and the Elsevier Bibliographic databases. The manuscript management system is completely online and includes a very quick and fair peer-review system, which is all easy to use. Visit $\mathrm{http}: / /$ www.dovepress.com/testimonials.php to read real quotes from published authors. 